\title{
Cocaine Intoxication-Clinical Findings from 402 Acute Deaths
}

\author{
Nnoli, M.A. ${ }^{1}$, Emeka, P. PhD ${ }^{2}$, Nwabuko C.O. ${ }^{3}$, Nnoli C. ${ }^{4}$ \\ ${ }^{I}$ Department of Anatomic and Forensic Pathology, University of Calabar,Calabar. ${ }^{2}$ College of Clinical \\ Pharmacy, King Faisal University, Kingdom of Saudi Arabia. ${ }^{3}$ Department of Haematology, Federal Medical \\ Center, Umuahia. Nigeria. ${ }^{4}$ Department of Pediatrics, University of Uyo, Uyo. Nigeria.
}

\begin{abstract}
The act of concealing illicit packets of drugs in body cavities for trafficking purposes is not only criminal but could prove to be a fatal venture. The most frequent cause of death among drug couriers is acute drug intoxication due to rupture of the packages inside the body. These illicit substances are often ingested with aids of balloons, condoms or plastic bags and in some cases packets are inserted into the rectum or vagina. In this report, we present a seven year study, from 402 autopsied victims spanning from 1999 - 2005 which included male and female cocaine couriers from Nigeria. A detailed autopsy was carried out on each body brought to the Pathology department. The different tissues and organs involved were studied and all pathological changes noted. In all the law enforcement agencies responsible for narcotics and other drugs were available before autopsy was carried out. The ratio of incidence of male to female was approximately 4:1. Results showed overwhelmed cerebral haemorrhage with massive oedema in the CNS. This trend was observed mostly among male couriers. Also the gastrointestinal tract revealed massive erosion of underlying mucosa with torrential haemorrhage. We also observed gross heart enlargement, severe pulmonary oedema and gross anthracotic patches in the lungs. Bitten tongues and multiple haemorrhages on serial cutting of the tongue were also observed. It should be noted therefore that materials used for concealment of these illicit drugs are not full proof. These can undergo damage while inside the body as we have seen, leading to acute intoxication due to mucosal absorption and death. Law enforcement agents should be suspicious of seizures and sudden deaths of would be travellers at airports. Massive campaign is needed by government to educate intending drug couriers on the dangers of this venture and the fatal consequences they might face in the process.
\end{abstract}

Keywords: Cocaine, autopsy, intoxication, illicit drug, haemorrhage, courier.

\section{INTRODUCTION}

Cocaine is a worldwide illicit drug and its use cuts across regions and continents. It is a potent addictive stimulant of natural origin extracted from the leaves of a shrub, Erythroxylon coca indigenous to the Andean highlands of America. Cocaine came into clinical use as a local anaesthetic agent in 1884, when Koller an ophthalmologist applied it as a topical anaesthesia in the eye (1). Later, in $20^{\text {th }}$ century, cocaine fell into disuse as pain blockers and safer anaesthetics were developed. Tragically, cocaine continues to be in use as a highly addictive and destructive street illicit drug.

The major routes of abuse include snuffing, smoking and injection (2). As law enforcement becomes more stringent, traffickers of cocaine also developed sophisticated ways of smuggling the drug across borders. Various ways are employed by drug couriers to evade the law in smuggling. They include muscle insertion at vastus medialis and lateralis, deltoids, vaginal, swallowing via packed substances in condoms, balloons and even per rectum insertion (3). Evidence suggests that those who smoke or inject cocaine are in great risks of acute respiratory problems ranging from coughing, shortness of breath and even severe chest pains with lung trauma and bleeding into the lung parenchymal tissues (4). It is known that addicts who inject cocaine are at risk for transmitting or acquiring HIV/ AIDS infections, if needles are shared which is always the case with most addicts (5). Cardiovascular system (CVS) is not spared in individuals who abuse cocaine as it can result to wide range of complications including angina pectoris, myocardial infarction, and sudden death as seen in most of these victims $(6,7)$. Evidence show that the principal effects on CVS are mediated via alpha adrenergic stimulation and could lead to an increase in determinants of myocardial oxygen supply caused by vasoconstrictions of epicardial coronary arteries and could cause arteriosclerosis $(6,8)$. Also, beta adrenergic blocking agents may exacerbate cocaine induced coronary arterial vasoconstrictions, thereby increasing the magnitude of myocardial ischaemia (9). Studies have shown that concomitant cigarette smoking worsens the deleterious effects of cocaine on myocardial oxygen supply and demand substantially (10) Schreiber et al ( 11 ) reported that cocaine abuse is associated with cerebrovascular events with infarction in the anterior spinal artery distribution and lower motor neuron injury spasticity of the lower extremities. Also Yan et al (12) showed that cocaine exposure decreased brain derived neurotropic factor (BDNF) function and resulted in neuronal cell death $(13,14)$. It is suggested that the euphoric and other effects of cocaine as experienced by addicts is in part due to interference with the function and activities of the limbic system in the central nervous system (CNS). The mechanism proposed for its deleterious effect is said to be enhanced oxidative stress within the frontal 
cortex and the striatum of the CNS (15). Exposure of neurones to cocaine induced oxidative stress is reported to cause apoptosis and this could be seen even $72 \mathrm{~h}$ post exposure as demonstrated in the human neuronal precursor cells (NPCs) $(15,16)$. From the foregoing, the implication is that the consequence of cocaine abuse is also in part due to the compromise of antioxidant capacity of the cells as in the aging brain (15). The symptoms include mydriasis, seizures, acute toxic psychosis and coma in various combinations (17). It is therefore suggested that law enforcement agents should view with suspicion frequent travellers who show signs like seizures or any signs consistent with cocaine toxicity and dies suddenly at the airport (18). These seizures were seen in series of autopsies examined showing bitten tongues and multiple haemorrhages on serial cutting of the tongue. Although Nigeria is fast becoming a transit for drug trafficking, no report of this nature has been made before to high light the seriousness of these acts (19). In this report, we present autopsy findings of bodies of 402 dead travellers from 1999 to 2005 (a seven year study) in Lagos Nigeria. We were to establish the cause of death as in most cases when death is sudden and unexplained in suspicious circumstances.

\section{METHOD}

This study covers 1999 to 2005 as this entails autopsy of the presented dead victims. A detailed autopsy was carried out on each available body; sexes were taken into cognizance and anatomical areas and systems where the drugs were found were also documented. Substances retrieved from their bodies were analysed. The different tissues and organs involved were examined and all pathological changes noted. Before performing any of the autopsies, the law enforcement agencies responsible for narcotics, police and customs were all present. All drugs retrieved were counted and handed over to the appropriate authority. All the victims were frequent travellers as noted from their travelling documents. Some of them died at check points while others died in detention. Deaths were due to rupture of packets of cocaine concealed in the body.

\section{RESULT}

All the cases reported here were during the seven year period of study (1999 -2005) and were caught by men of law enforcement agency at the airport. Most apparently died in custody or slumped on check points of airports. These made it imperatively difficult for detailed investigation to be done by relevant agencies. There was increased incidence in the rate of male trafficking when compared to females. One of our constrained was about age distribution of the victims and because of the sensitive nature of the cases little information about the victims were divulged. Therefore there were no case notes hence verbal history was taken and this is not adequate to characterise the cases for future use or statistic. Toxicological analysis was done using GC/MS-LC and samples were positive for cocaine.

\section{AUTOPSY FINDINGS}

Raps of white powder (later identified as cocaine) in latex and condoms were found concealed in various body cavities, with some of them ruptured. The findings showed bitten tongues and multiple haemorrhages on serial cutting of the tongue. Most of the heart samples weighed between 400 to $650 \mathrm{gms}$ for both sexes. The normal for male and female are 300 to $350 \mathrm{gms}$ and 250 to $300 \mathrm{gms}$ respectively. The brain weighs within the normal range of $1 \mathrm{~kg}$ to $1.2 \mathrm{~kg}$ and most are above staggering from 1.5 and above. All however has some degree of cerebral oedema from mild, moderate to severe. Systems mostly affected with distinct pathology were the gastrointestinal tract (GIT), respiratory system (RS), cardiovascular system (CVS) and central nervous system (CNS). The GIT was the most prominent parts where recovery of the materials took place. Drug was found in the gut, small intestine and large intestine, while in others it was seen at the verge of the stomach getting down through pyloric sphincter. That may have contributed to excessive vomiting with foaming in the mouth. All the victims $(100 \%)$ concealed the drug by swallowing already packed cocaine in latex membranes or condoms hence rupturing of these substances in stomach and intestines causing massive erosion of underlying mucosa (paper thin) with torrential haemorrhages. In the respiratory system, there were gross anthracotic patches distributed discretely and lungs were heavier weighing greater than 1000 gm wet and shiny (glassy). This appears to be consistent with severe pulmonary oedema (98\%). Serial sectioning of the lungs showed congested parenchymal tissues. On the CVS we found the heart to be grossly enlarged in about $91 \%$ of the victims with series of cardiomegaly with a consequent heart failure. It is believed to have affected the circulatory function of the heart thus producing a decrease in the oxygenation of the blood and increased the workload of the heart.

In most of the cases autopsied CNS showed overwhelmed cerebral haemorrhages in about $87 \%$ of victims. In about $15 \%$ of bodies examined, massive cerebral oedema was seen suggested to be cytotoxic with gross tonsilar herniation thus compromising the vasomotor/baroreceptors centres.

V. DISCUSSION

Findings revealed that most of the victims used various routes namely, muscle insertion at vastus medialis and lateralis, deltoids, vaginal, swallowing of packed cocaine in condoms, balloons and per rectum 
insertion of the illicit drug. This has been shown in other reports (3). However, the most frequent cause of death is acute drug intoxication due to rupture of packages within the body.

It is worthy to note that out of 402 bodies autopsied, 345 were males representing a total $86 \%$ (for all the years) of the victims showing them to be more risk takers than the females [table 1 and figure 1].The sudden slumping seen in $95 \%$ of cases may be due to seizures as was seen with bitten tongues and multiple haemorrhages on serial cutting of the tongue. This observation is consistent with the work of those (20) who described seizure as a major component of cocaine intoxication. A body of evidence associates seizure with cocaine intoxication $(18,20)$. Report indicates that cocaine lowers seizure threshold in the brain and there is evidence that cocaine can incite seizure or cause an ischemic or hemorrhagic stroke that provoke seizures (18). These effects have been suggested to be due to abnormalities in the $\gamma$-aminobutyric acid (GABA) system (21).

In others, there were reported loss of consciousness and then death. Our observation vasoconstriction was similar to the findings of Lang et al., (7). They maintained that these effects were mediated via alpha adrenergic stimulation due to an increase in determinants of myocardial oxygen demand and concomitant decrease in myocardial oxygen supply. There were also vasoconstrictions of epicardial coronary arteries in the autopsied victims. Observation of marked fluidity and vasoconstrictions is thought to be enhanced by artheriosclerosis (4). This feature of disseminated intravascular coagulation (fluidity of blood) may be due to release of tissue factor or thromboplastic substances into the circulation and widespread injury to the endolethlial cells as seen in cases of rupture (22). Furthermore we observed massive necrosis with active gastrointestinal bleeding in all the victims with ruptured drug packets. Similar report of cocaine associated GIT bleeding have been documented in past $(23,24)$. It is suggested that massive GIT bleeding could contribute to high mortality rate seen in drug packers with ruptured contents $(25,26)$

A wide range of pathological effects were seen in CNS during autopsy that ranged from intracerebral haemorrhages to ischaemic changes (encaphalomalacia). This is in agreement with the findings of Schreiber et al., (11). Part of the findings was cerebral oedema in the victims and it was also consistent with the observations of Yan et al ( 12 ) in which he reported that the cause was due to cytotoxicity of cocaine in brain derived neurotropic factors and could be associated with oxidative stress (27). Pulmonary toxicity was also prominent with pulmonary oedema which showed upon serial sectioning congested parenchymal tissues. This observation was also consistent with the histology findings of Todorović et al., (28).

There are few other causes not discernible immediately such as biochemical derangements and early stages of septicaemia as these have to be borne in mind and excluded by effective adjunctive investigations. It is essential that all suspected cases of drug overdose/addict are autopsied so that effective clinical management will be instituted and constantly evaluated for proper care.

\section{CONCLUSION}

The findings presented in this report indicate that acute cocaine intoxication from concealment affects multiple organ systems and leads to fatal consequences.

The greatest limitation of this study is lack of autopsy on the bodies from other international airports in the country due to politics, hush-hush nature of investigations by security agents and lack of effective toxicology centres to analyse the samples from victims to ascertain body burden of cocaine at the time of death. It takes months before samples sent abroad (not in all cases and this is usually determined by police which victim's samples to send) are brought back due to bureaucracy within the government. Responsible authorities are not obliged to share the findings when results are received, which would have helped scientist to learn more from these events and perhaps improve on how to help victims. Hence, cases take longer time to resolve or dispose of due to either inactivity or lack of security agents. It is pertinent to note that some of these victims also died in detention as we gathered from the relatives. Finally, attention should be focused on media education on the dangers of drug trafficking and its attendant fatal consequences.

\section{REFERENCES}

[1]. Goerig M, Bacon D, van Zundert A. Carl Koller, cocaine, and local anaesthesia: some less known and forgotten facts. Reg Anesth Pain Med 37(3) (2012) 318-24.

[2]. Gossop M, Griffiths P, Powis B, Strang J. Severity of dependence and route of administration of heroin, cocaine and amphetamines. Br J Addict 87(11) (1992) 1527-36.

[3]. Celiński R, Jabłoński C, Skowronek R, Korczyńska M, Kulikowska J, Nowicka J, Chowaniec C, Uttecht-Pudełko A. Smuggling of the cocaine in the gastrointestinal tract ended in sudden death--the first case report from the Upper Silesia. Wiad Lek 64 (2011) 109-12.

[4]. Richard A. Lange, M.D., Ricardo G. Cigarroa, M.D., Clyde W. Yancy, Jr., M.D., John E. Willard, M.D., Jeffrey J. Popma, M.D., Michael N. Sills, M.D., Wade McBride, M.D., Anatole S. Kim, M.D., and L. David Hillis, M.D. Cocaine-Induced Coronary-Artery Vasoconstriction. N Engl J Med 321 (1989) 1557-1562.

[5]. Des Jarlais DC, Arasteh K, Perlis T, Hagan H, Abdul-Quader A, Heckathorn DD, McKnight C, Bramson H, Nemeth C, Torian LV, Friedman SR. Convergence of HIV seroprevalence among injecting and non-injecting drug users in New York City. AIDS Jan 11 21 (2007)231-5. 
[6]. Theodore E, Woodward Award: Cardiovascular complications of cocaine abuse. Trans AM clin clinatol Assoc 115 (2004) 99 114.

[7]. Lange RA, Cigarroe JE, Hilis ID: Cardiovascular complications of cocaine abuse. Trans American clinical climatol Assoc 2004 $158-172$.

[8]. Carpentier RG, Coleman BR, Patel DJ. Adrenergic-mediated effects of cocaine on the myocardial force-frequency relationship. Life Sci 63 (1998) 859-69.

[9]. Santos, s., Brugal, m. t., Barrio, g., Castellano, y., Domingo-salvany, a., Espelt, a., Bravo, m. j., de la Fuente, 1. and the Itinere project group. Assessing the effect of patterns of cocaine and alcohol use on the risk of adverse acute cocaine intoxication. Drug and Alcohol Review 31 (2012) 439-446.

[10]. Levine A., Y. Huang, B. Drisaldi, E. A. Griffin, D. D. Pollak, S. Xu, D. Yin, C. Schaffran, D. B. Kandel, E. R. Kandel, Molecular Mechanism for a Gateway Drug: Epigenetic Changes Initiated by Nicotine Prime Gene Expression by Cocaine. Sci Transl Med 3 (2011) 107-09.

[11]. Schreiber AL, Formal CS: Spinal cord infarction secondary to cocaine use. America journal phys med rehabil 86(2) (2007) 158 60.

[12]. Yan QS, Feng MJ, Yan SE : RNA interference - mediated inhibition of brain - derived neurotropic factor expression increases cocaine's toxicity in cultured cells. Neuroscience let 414(2) (2007) $165-9$.

[13]. Lee CT, Chen J, Hayashi T, Tsai SY, Sanchez JF, Errico SL, Amable R, Su TP, Lowe RH, Huestis MA, Shen J, Becker KG, Geller HM, Freed WJ. A mechanism for the inhibition of neural progenitor cell proliferation by cocaine. PLoS Med 5(2008) e117.

[14]. McCarthy D. M., Zhang X., Darnell S. B., Sangrey G. R., Yanagawa Y., Sadri-Vakili G., Bhide P. G.. Cocaine alters BDNF expression and neuronal migration in the embryonic mouse forebrain. J. Neurosci 31 (2011)13400-13411.

[15]. Poon HF, Abdulahi L, Mullan MA, Mullan MJ, Crawford: cocaine induced oxidative stress proceeds cell death in progenitor cells. Neurochem int 50 (2007) 69 -73.

[16]. Shuxian Hu, Maxim C.-J. Cheeran, Wen S. Sheng, Hsiao T. Ni, James R. Lokensgard, and Phillip K. Peterson. Cocaine Alters Proliferation, Migration, and Differentiation of Human Fetal Brain-Derived Neural Precursor Cells. J Pharmacol Exp Ther 318 (2006) 1280-1286.

[17]. de Bakker JK, Nanayakkara PW, Geeraedts LM Jr, de Lange ES, Mackintosh MO, Bonjer HJ. Body packers: a plea for conservative treatment. Langenbecks Arch Surg 397 (2012)125-30.

[18]. Koppel, B. S., Samkoff, L. and Daras, M. Relation of Cocaine Use to Seizures and Epilepsy. Epilepsia 37 (1996) 875-878.

[19]. George W Bush http://allafrica.com/stories/200709190692.html ( 2007).

[20]. Majlesi N, Shih R, Fiesseler FW, Hung O, Debellonio R. Cocaine-associated seizures and incidence of status epilepticus. West J Emerg Med 11 (2010) 157-160.

[21]. Reid, Malcolm S and Thakkar, Vatsal. Valproate treatment and cocaine cue reactivity in cocaine dependent individuals. Drug and alcohol dependence ISSN 0376-8716 102 (2009) $144-150$.

[22]. Thijis LG, et al: Coagulation disorders in septic shock. Intensive care Med 19 (1993) S8.

[23]. Wincher, Glenn. Drug-Related Deaths with Evidence of Intracorporeal Drug Concealment at Autopsy: Five Case Reports. American Journal of Forensic Medicine \& Pathology 32 (2011) 314-318.

[24]. Gibbons TE, Sayed K, Fuchs GJ. Massive pan-gastrointestinal bleeding following cocaine use. World J Pediat 5(2) (2009) 149-51.

[25]. Lingamfelter DC, Knight LD. Sudden death from massive gastrointestinal hemorrhage associated with crack cocaine use: case report and review of the literature. Am J Forensic Med Pathol 31 (2010) 98-99.

[26]. Koehler S.A., Ladham S., Rozin L., Shakir A., Omalu B., Dominick J., Wecht C.H. The risk of body packing: A case of a fatal cocaine overdose. Forensic Science International 151 (2005) 81-84.

[27]. Macedo D.S., Vasconcelos S.M.M., Andrade-Neto M., Belchior L.D., Junior J.E.R.H., Goncalves D.O., Fonteles M.M.F. de Sousa F.C.F. Cocaine-induced status epilepticus and death generate oxidative stress in prefrontal cortex and striatum of mice. Neurochemistry International 56 (2010) 183-187.

[28]. Todorović MS, Mitrović S, Aleksandrić B, Mladjenović N, Matejić S. Association of pulmonary histopathological findings with toxicological findings in forensic autopsies of illicit drug users. Vojnosanit Pregl 68 (2011) 639-42.

Table 1 No. of autopsies conducted for 7 years showing sex distribution.

$\begin{array}{cccccccc}\text { Year } & 1999 & 2000 & 2001 & 2002 & 2003 & 2004 & 2005 \\ \text { Male } & 20 & 50 & 35 & 70 & 48 & 70 & 52 \\ \text { Female } & 5 & 10 & 6 & 15 & 12 & 6 & 3 \\ \text { Total } & 25 & 60 & 41 & 85 & 60 & 76 & 55\end{array}$

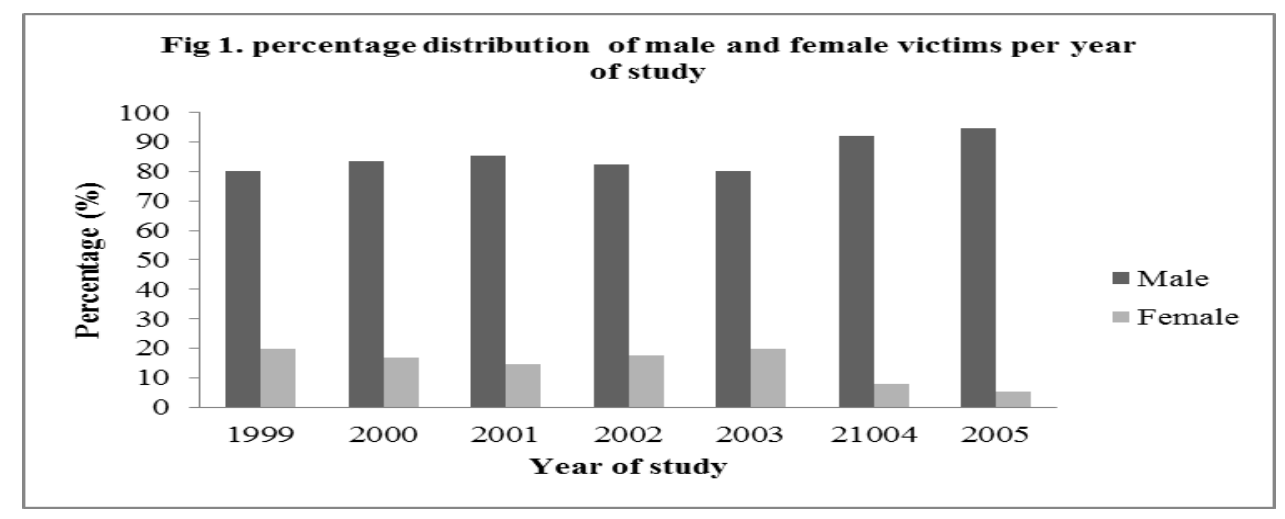




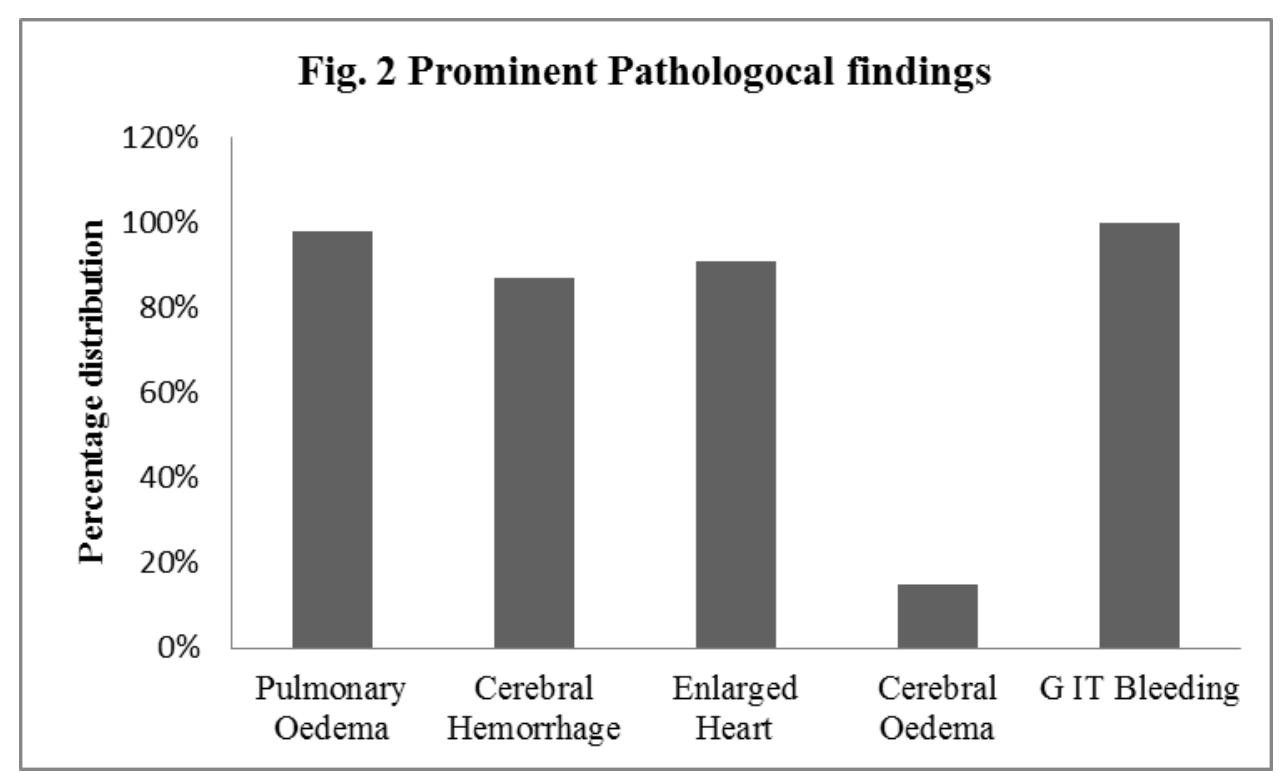

